
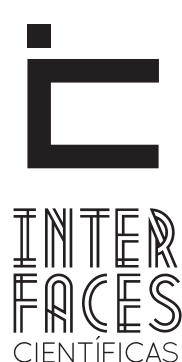

SA ÚDE E AMBIENTE

\title{
A PROBLEMÁTICA DOS RESÍDUOS SÓLIDOS URBANOS
}

Ronise Nascimento de Almeida ${ }^{1}$ Alceu Pedrotti ${ }^{2}$
Daniela Venceslau Bitencourt ${ }^{3}$ Luiz Carlos Pereira Santos ${ }^{4}$

\section{RESUMO}

A maioria das cidades no Brasil e no mundo vem enfrentando sérios problemas relacionados à geração de resíduos e a falta de conhecimento sobre alternativas para o destino final dos resíduos sólidos urbanos, consideráveis transtornos á população e ao meio ambiente. Este artigo visa contextualizar a classificação dos resíduos, bem como abordar diferentes alternativas de tratamento como: aterro sanitário, incineração, compostagem, biogasificação e reciclagem. Dentro deste proposito, a metodologia utilizada neste estudo foi realizada fundamentalmente por intermédio de revisão bibliográfica e analise documental. Assim, a correta classificação, caracterização e tratamento dos resíduos tornam-se fundamentais para uma nova forma de gerenciamento, incorporando os princípios da sustentabilidade, que apresente resolução de problemas e que possibilite transformações de situações de vulnerabilidades dos grupos afetados, portanto, o bom gerenciamento dos resíduos sólidos é considerado como importantes formas de evitar poluição ao meio ambiente e melhorar a qualidade de vida da população.

\section{PALAVRAS-CHAVE}

Resíduos. Classificação. Tratamento. 


\section{ABSTRACT}

Most cities in Brazil and the world is facing serious problems related to waste generation and the lack of knowledge about alternatives to the final destination of urban solid waste, considerable inconvenience to the population and the environment. This article seeks to contextualize the classification of waste as well as addressing different treatment alternatives such as landfill, incineration, composting, methanisation, and recycling. Within this purpose, the methodology used in this study was mainly performed through bibliographic review and documentary analysis. Thus, the correct classification, characterization and treatment of waste become fundamental to a new form of management, incorporating the principles of sustainability, which makes troubleshooting and enabling transformation of situations of vulnerability of affected groups, therefore, the proper solid waste management is considered as important ways to prevent pollution to the environment and improve the quality of life.

\section{KEYWORDS}

Waste. Rating. Treatment.

\section{RESUMEN}

La mayoría de las ciudades de Brasil y del mundo se enfrenta a graves problemas relacionados a la generación de residuos, y a la falta de conocimientos sobre las alternativas y el destino final de los residuos sólidos, considerables como algo insano a la población y el medio ambiente. Este artículo tiene como afán contextualizar la clasificación de los residuos, así como hacer frente a las diferentes alternativas de tratamiento, tales como vertederos, incineración, compostaje, reciclaje y el biogás. Dentro de este objetivo, la metodología utilizada para estudio, se llevó a cabo principalmente a través de revisión bibliográfica y análisis documental. Por lo tanto, la correcta clasificación, caracterización y tratamiento de residuos, se convierten en pilares fundamentales para una nueva forma de gestión, incorporando los principios de la sostenibilidad, lo que se podría materializar como una solución a los problemas y permitir el cambio de las situaciones de vulnerabilidad de los grupos afectados. Se considera que la buena gestión de los residuos sólidos, son aspectos sumamente importantes para prevenir la contaminación del medio ambiente y mejorar la calidad de vida.

\section{PALABRAS CLAVE}

Residuos. Rating. Tratamiento.

\section{INTRODUCÇÃO}

A história do lixo se confunde com a história do ser humano; no início dos tempos, os primeiros homens eram nômades. Morava em cavernas, sobreviviam da caça e da pesca; quando a comida começava a ficar escassa, eles se mudavam para outra região, e seus lixos deixados sobre o meio ambiente eram logo decompostos pela ação do tempo. Após a descoberta de que podia cultivar sementes de trigo, cevada e outros vegetais, o nomadismo gradativamente cedeu lugar para o sedentarismo, o homem foi civilizando-se, passou a produzir artigos diversos para o seu conforto, além de fixar-se de forma permanente em um local. 0 desenvolvimento acentuou-se naturalmente com o passar dos anos e, consequentemente, ocasionou o acréscimo da produção de resíduos (JAMES, 1992).

Durante a Idade Média, o acúmulo de pessoas nas cidades foi aumentando significativamente, e com ele surge à necessidade do desenvolvimento de novos produtos, cujo objetivo principal encontrava-se fortemente relacionado ao suprimento das necessidades humanas, gerando ambientes propícios à difusão do progresso. As cidades representam o cenário ideal para o consumo 
dos mais variados produtos, e, quanto mais se consome, consequentemente, há uma maximização no volume dos resíduos, além de restos de comida, grandes quantidades de excremento animal e humano, surgindo assim, ambiente ideal para a proliferação de ratos e a manifestação de doenças e epidemias. A mais grave, registrada, foi a peste negra, que entre os anos de 1347 e 1351 causou 25 milhões de mortes, compreendendo um terço da população europeia. (NOVA ESCOLA, 2003)

A partir de 1750, com a revolução industrial, as fábricas começaram a produzir objetos de consumo em larga escala e a introduzir novas embalagens no mercado, aumentando consideravelmente o volume e a diversidade de resíduos gerados nas áreas urbanas. Ao mesmo tempo, o crescimento acelerado das metrópoles fez com que as áreas disponíveis para colocar o lixo se tornassem cada vez mais escassos. A sujeira acumulada no ambiente aumentou a poluição do solo, das águas e do ar, agravando as condições de saúde em todo o mundo e causando sérios impactos negativos ao meio ambiente.

Entretanto, a partir da segunda metade do século XX iniciou-se uma reviravolta. A humanidade passou a preocupar-se de forma mais contundente com o futuro do planeta, porém, não foi por acaso: fatos como o buraco da camada de ozônio e o aquecimento global da terra despertam a população mundial sobre o que estava acontecendo com o meio ambiente. Nesse despertar, a questão da geração e destinação final do lixo foi percebida (JAMES, 1992).
Mas o que vem a ser lixo? De acordo com Consoni et al (2002, p.29), "denomina-se lixo os restos das atividades humanas, considerados pelos geradores como inúteis, indesejáveis ou descartáveis”. Normalmente, apresenta-se em estado sólido, semissólido ou semilíquido (com conteúdo líquido insuficiente para que este possa fluir livremente). Nos argumentos apresentados por Gonçalves, destaca que:

\begin{abstract}
[...] Todos os processos geram resíduos, desde o mais elementar processo metabólico de uma célula ate 0 mais complexo processo de produção industrial. Por outro lado, a lata de lixo não é um desintegrador mágico. A humanidade vive em ciclos de desenvolvimento e neste momento estamos vivendo um ápice de desperdício e irresponsabilidade na extração dos recursos naturais esgotáveis (GONÇALVES, 2003, p.19).
\end{abstract}

Considerando que o lixo é constituído por uma parcela de materiais recicláveis, podemos então afirmar que o lixo não é apenas tudo aquilo que não presta. No lixo existem valores a serem resgatados por intermédio das práticas do não desperdício, da separação na fonte e do fomento à cadeia produtiva da reciclagem. Ao se considerar a caracterização do lixo, é importante lembrar que suas características variam ao longo de seu percurso pelas unidades de gerenciamento do lixo desde a geração até o destino final, bem como ao longo do tempo. Segundo Bojadsen (1997), para determinar o melhor aproveitamento ou destinação final do lixo é necessário conhecer a sua origem e classificação, conforme as descrições apresentadas na tabela 1:

\section{Tabela 1: Classificação do Lixo}

\begin{tabular}{l|l}
\hline Lixo Domiciliar & Resíduos sólidos de atividades residenciais. \\
\hline Lixo Comercial & Resíduos sólidos das áreas comerciais. \\
\hline Lixo Público & Resíduos sólidos de produto de limpeza pública. \\
\hline Lixo de Serviços de Saúde & Resíduos hospitalares, ambulatoriais e farmácias. \\
\hline Lixo Industrial & Resíduos produzidos pela indústria. \\
\hline Lixo Agrícola & Resíduos das atividades agrícolas e da pecuária. \\
\hline Lixo Entulho & Resíduos da construção civil. \\
\hline
\end{tabular}

Fonte: Autores, baseado em Consoni et al. (2002). 
Na concepção técnica, o lixo deve ainda ser visto e analisado sob o prisma biológico, sendo classificado como orgânico, inorgânico e tóxico. O lixo orgânico é todo lixo que tem origem animal ou vegetal, ou seja, que recentemente fez parte de um ser vivo. Numa linguagem mais técnica e moderna, abordam-se os resíduos sólidos, sendo seu componente biológico a matéria orgânica, mas da mesma forma oriundos dos seres vivos, sejam eles animais ou vegetais. Neles podem-se incluir restos de alimentos, folhas, sementes, restos de carne e ossos, papéis, madeiras etc. (BOJADSEN, 1997). Mesmo na atualidade, esse tipo de lixo é considerado poluente, devido aos componentes oriundos de seu processo de decomposiçao que além de ser altamente inatrativo, mal-cheiroso, cria um ambiente propício ao desenvolvimento de microorganismos, ponderados como grandes agentes causadores de desequilibrios na saúde humana.

O principal componente do lixo orgânico é o lixo humano, composto pelos resíduos produzidos pelo corpo humano, tais como fezes e urina. O lixo humano pode ser altamente perigoso, principalmente quando descartados em locais inadequados, uma vez que pode abrigar e transmitir com facilidade uma grande variedade de vermes, bactérias, fungos e vírus causadores de doenças e de desequilíbrios no meio ambiente. No entanto, uma realização primária da civilização humana tem sido a redução da transmissão de doenças através do lixo humano, graças à higiene e o saneamento básico.

Por outro lado, o lixo orgânico pode ser seletivizado e usado para diversos fins, como adubo - a partir da compostagem - ou utilizado para a produção de certos combustíveis como biogás, que é rico em metano - a partir da biogasificaçao - (JAMES, 1992), também pode ser utilizados na fabricação de briquetes, artesanato, na alimentação de animais, reduzindo a quantidade de descarte final do lixo orgamico e consequentemente minimizando o seu potencial poluidor.

Os resíduos inorgânicos incluem todo material que não possui origem biológica, ou que foi produzida através de meios humanos, como plásticos, metais e ligas, vidro, etc. Considerando a conformação da natureza, os materiais inorgânicos são representados pelos minerais. Muito do lixo inorgânico possui um grande problema: quando jogado diretamente no meio ambiente, sem tratamento prévio, demora muito tempo para ser decomposto. 0 plástico, por exemplo, é constituído por uma complexa estrutura de moléculas fortemente ligadas entre si, o que torna difícil a sua degradação e posterior digestão por agentes decompositores (BOJADSEDN, 1997).

0 resíduo tóxico é o material descartado, geralmente na forma química, que pode causar a morte ou danos aos seres vivos. Normalmente são resíduos oriundos da indústria e comércio, porém também podem ser resíduos de origens residenciais, da agricultura, militar, hospitalar, fontes radioativas, bem como os detritos derivados das lavanderias e tinturarias geralmente são grandes forças poluidoras, principalmente quando descartados e/ou utilizados de maneira inadequada, podendo causar impactos negativos irrevesiveis, tanto na natureza quanto na sociedade, reduzindo o nível de qualidade de vida da população. 


\section{RESULTADOS E DISCUSSÕES}

\subsection{ATERRO SANITÁRIO}

Um aterro sanitário é uma forma para a deposição final dos resíduos sólidos gerados pelas atividades humanas. Nele são dispostos resíduos domiciliares, comerciais, de serviços de saúde, da indústria, ou dejetos sólidos retirados do esgoto (D’ALMEIDA, 2002). Segundo a Associaçao Brasileira de Normas e Técnicas (ABNT), os aterros sanitários de resíduos sólidos urbanos consistem:

[...] na técnica de disposição de resíduos sólidos urbanos no solo, sem causar danos ou riscos à saúde pública e à segurança, minimizando os impactos ambientais, método este que utiliza os princípios de engenharia para confinar os resíduos sólidos ao menor volume permissível, cobrindo-os com uma camada de terra na conclusão de cada jornada de trabalho ou a intervalos menores se for necessário.

Os aterros são adequados para a recepção de resíduos de origem doméstica, varrição de vias públicas e comércios. Os resíduos industriais devem ser destinados a aterro de resíduos sólidos industriais (enquadrado como classe II quando não perigoso e não inerte e classe I quando se tratar de resíduo perigoso, de acordo com a norma técnica da ABNT 10.004/04 “Resíduos Sólidos - Classificação”).

A base do aterro sanitário deve ser constituída por um sistema de drenagem de efluentes líquidos percolados (chorume) acima de uma camada impermeável de polietileno de alta densidade (Pead), sobre uma camada de solo compactado para evitar o vazamento de material líquido para o solo, evitando assim a contaminação de lençóis freáticos. 0 chorume deve ser tratado e/ou recirculado (reinserido ao aterro) causando assim uma menor poluição ao meio ambiente. Seu interior deve possuir um sistema de drenagem de gases que possibilite a coleta do biogás, que é constituído por metano, gás carbônico(CO2) e água (vapor), entre outros, e é formado pela decomposição dos resíduos.
Este efluente deve ser queimado ou beneficiado, já os gases podem ser queimados na atmosfera ou aproveitados para geração de energia. No caso de países em desenvolvimento, como o Brasil, a utilização do biogás pode ter como recompensa financeira a compensação por créditos de carbono ou CERs do Mecanismo de Desenvolvimento Limpo, conforme previsto no Protocolo de Quioto, como já é efetuado por diversos aterros sanitários no Brasil, a saber: aterro de Nova Iguaçu, aterros Bandeirantes e São João em São Paulo, Embralixo-Arauna em Bragança Paulista, entre outros.

Sua cobertura é constituída por um sistema de drenagem de águas pluviais, que não permita a infiltração de águas de chuva para o interior do aterro. Com a compactação de resíduos no aterro é possível a produção de gás, podendo assim diminuir a exploração de combustiveis fósseis. Este processo de produção é utilizado largamente em países da Europa como Portugal, na zona de Leiria, no qual recebeu a denominação de "Projecto - Residuos + Petróleo".

Um aterro sanitário deve também possuir um sistema de monitoramento ambiental (topográfico e hidrogeológico) e pátio de estocagem de materiais. Para aterros que recebem resíduos de populações acima de 30 mil habitantes, é desejável também muro ou cerca limítrofe, sistema de controle de entrada de resíduos (ex. balança rodoviária), guarita de entrada, prédio administrativo, oficina e borracharia (D’ALMEIDA, 2002). Faz-se mister ressaltar que há critérios de distância mínima de um aterro sanitário e um curso de água, uma região populosa e assim por diante. No Brasil, recomenda-se que a distância mínima de um aterro sanitário para um curso de água deve ser de $400 \mathrm{~m}$. 
A recepção dos resíduos inicia-se com a entrada do veículo de transporte de resíduos no aterro sanitárioe a pesagem na balança. Depois de feito o controle na entrada e efetuada a pesagem, o veículo desloca-se até a zona de deposição, avança até a frente de trabalho, procedendo a descarga dos resíduos. Em seguida, o veículo passa pela unidade de lavagem dos rodados (quando houver) e é novamente pesado para a obtenção da tara, de forma a ficar registado o peso líquido da quantidade de resíduo transportada (D’ALMEIDA, 2002).

A operação segura de um aterro sanitário envolve empilhar e compactar os resíduos sólidos e cobrí-lo diariamente com uma camada de solo. A compactação tem como objetivo reduzir a área disponível prolongando a vida útil do aterro, ao mesmo tempo em que o propicia a firmeza do terreno possibilitando seu uso futuro para outros fins. A cobertura diária do solo evita que os resíduos permaneçam a céu aberto, com possível contato com animais (pássaros) e sujeito a chuva, e também para diminuir a liberação de gases mal cheirosos, bem como a disseminação de doenças (D’ALMEIDA, 2002).

Quando atinge o limite de capacidade de armazenagem, o aterro pode ser alvo de um processo de monitorização específico, e se reunidas as condições, pode albergar espaços verde ou mesmo parque de lazer, eliminando assim o efeito estético negativo e transformando-se em espaços multifuncionais atrativos á população. Uma das principais vantages do aterro é o facto de poder ser deslocado de um lugar para outro sem prejudicar a vida animal. Recentemente foi encontrada uma célula produzida em aterros que contribui para o fortalecimento do sistema imunitário, podendo assim contribuir na descoberta da cura de diversos tipos de doenças (D’ALMEIDA, 2002).

\subsection{INCINERAÇ̃̃O}

Um incinerador elimina resíduos, domésticos, industriais ou hospitalares, através do uso de altas temperaturas (que variam entre 800 e três mil ${ }^{\circ} \mathrm{C}$ ), gerando enorme quantidade de poluição atmosférica, especialmente dióxido de carbono, identificado como agente causador do efeito estufa (CONSONI, 2002).

\subsection{COMPOSTAGEM}

Segundo Silva (2000) a compostagem é um conjunto de técnicas aplicadas para controlar a decomposição de materiais orgânicos, com objetivo de obter, no menor tempo possível, um material estável, rico em húmus e nutrientes minerais, com atributos físicos, químicos e biológicos superiores (sob o aspecto agronômico) àqueles pesente(s) na(s) matéria(s) prima(s).

Para D’Almeida (2002), a incineração é um processo de combustão controlada dos resíduos, cuja finalidade principal é a eliminação total dos resíduos tóxicos ao meio ambiente, onde não deverá ocorrer a emissão de gases tóxicos para a atmosfera. Para tanto, deverão ser empregados precipitadores de partículas, filtros eletrostáticos, lavadores de gases, etc.

Encontrar um destino sustentável para o lodo de esgoto (ou biossólido) ainda é um desafio para as empresas geradoras e seus colaboradores. Muitas vezes, o envio do resíduo para um aterro sanitário torna-se a maneira mais prática de solucionar a questão do destino, mas esta via nem sempre se mostra a mais econômica, a mais segura ou a melhor escolha do aspecto ambiental. 
O uso agronômico do lodo de esgoto (biossólido), como fonte de matéria orgânica e nutriente para as culturas, respeitando-se as exigências normativas estabelecidas pelos órgãos fiscalizadores, não tem desapontado seus geradores nem tampouco seus receptores (D’ALMEIDA, 2002).

No processo de compostagem, que se completa após a formação do húmus, assegura Silva (2000), pode-se reconhecer três fases distintas:

a) rápida decomposição de certos constituintes pelos microrganismos.

b) síntese de novas substâncias criadas pelos microrganismos.

c) formação de complexos resistentes em razão dos processos de condensação e polimerização. Resíduos vegetais e animais não são igualmente atacados, nem se decompõem inteiramente de uma só vez; seus diversos constituintes são decompostos em diferentes estágios, com diferentes intensidades e por diferentes populações de microrganismos. Os açúcares, os amidos e as proteínas solúveis são decompostos em primeiro lugar, seguindo-se de algumas hemiceluloses e demais proteínas. Celulose, certas hemiceluloses, óleos, gorduras, resinas e outros constituintes das plantas são decompostos mais demoradamente. As ligninas, certas graxas e taninos são os materiais considerados mais resistentes à decomposição.

Enquanto houver decomposição aeróbia, o carbono será liberado como gás carbônico, entretanto, se o processo tornar-se anaeróbio, eliminar-se-ão, além do $\mathrm{CO} 2$, metano, álcool e ácidos orgânicos. As proteínas, por decomposição, são primeiramente hidrolisadas por enzimas proteolíticas produzidas pelos microrganismos, gerando polipeptídios, aminoácidos e outros derivados nitrogenados; o nitrogênio orgânico é convertido à forma amoniacal. Ao final do processo obtém-se o húmus, ou seja, uma substância escura, uniforme, amorfa, rica em partículas coloidais, pro- porcionando a este material, propriedades físicas, químicas e físico-químicas diferentes da matéria-prima original. 0 tempo médio para que a pilha original se decomponha até a bioestabilização é de 30 a 60 dias. Para a completa humificação, serão necessários mais 30 a 60 dias. Desta forma, para completar-se o processo na pilha, serão necessários aproximadamente 90 dias (SILVA, 2000).

Para aplicação no solo, a utilização do material bioestabilizado é justificada por três motivos: ao passar pela fase termófila haverá a destruição de ovos, larvas e microrganismos patogênicos que, porventura puderem existir na massa inicial; ao apresentar relação C / N abaixo de 20 ainda haverá atividade biológica, mas não haverá o "sequestro" do nitrogênio do solo para completar o processo; a temperatura não é alta o suficiente para causar danos às raízes ou às sementes (D’ALMEIDA, 2002).

Segundo Silva (2000), a velocidade e o grau de decomposição dos resíduos orgânicos podem ser medidos de várias maneiras:

\section{Quantidade de $\mathrm{CO} 2$ desprendido \\ 2. Diminuição da relação $\mathrm{C} / \mathrm{N}$ \\ 3. Ciclo da temperatura \\ 4. Elevação e estabilização do pH}

Sendo um processo biológico, as transformações ocorrem de acordo com os princípios já mencionados. No entanto, os métodos variam de sistemas particularmente artesanais, até sistemas complexos, onde os fatores interferentes são monitorados e controlados com relativa precisão. Os sistemas de compostagem, segundo Fernandes (2000), agrupam-se em três categorias:

a) Sistemas de leiras revolvidas (Windrow): A mistura de resíduos é disposta em leiras, sendo a aeração fornecida pelo revolvimento dos materiais e pela convecção do ar na massa do composto. 
b) Sistema de leiras estáticas aeradas (Static pile): A mistura é colocada sobre tubulação perfurada que injeta ou aspira o ar na massa do composto. Neste caso, não há revolvimento mecânico das leiras.

c) Sistemas fechados ou reatores biológicos (In-vessel): Os materiais são colocados dentro de sistemas fechados, que permitem o controle de todos os parâmetros do processo de compostagem.

Kiehl (1985) classificou os sistemas de compostagem também quanto ao tempo. Neste caso os proces-

\subsection{BIOGASIFICAÇÃO}

Para D’Almeida (2002), a biogasificação ou metanização é um tratamento de resíduos orgânicos por decomposição ou digestão anaeróbica que gera biogás, que é formado por cerca de 50\%-60\% de metano e que pode ser queimado ou utilizado como combustível. Os resíduos sólidos da biogasificação podem ser tratados aerobicamente para formar composto.

Segundo Gunnerson (1986), a digestão anaeróbica é o processo de decomposição orgânica onde as bactérias anaeróbicas, que apenas sobrevivem na ausência de oxigênio, conseguem rapidamente decompor os resíduos orgânicos. Quatro estágios da digestão anaeróbica são reconhecidos:

\subsection{RECICLAGEM}

A reciclagem é o reaproveitamento dos materiais como matéria-prima para um novo produto. Muitos materiais podem ser reciclados e os exemplos mais comuns são o papel, o vidro, o metal e o plástico. As maiores vantagens da reciclagem são a minimização da utilização de fontes naturais, muitas vezes não renováveis; e a minimização da quantidade de resíduos sos são lentos ou acelerados. Consideram-se lentos, aqueles os quais a matéria-prima é disposta em montes nos pátios de compostagem após sofrer separação de materiais não decomponíveis, como é o caso dos resíduos domiciliares, recebendo revolvimentos periódicos para arejar e ativar a fermentação. Os processos acelerados são os que proporcionam tratamento especial à matéria-prima, melhorando as condições para fermentação, principalmente o arejamento e o aquecimento. A compostagem em pátio, com injeção de ar nas pilhas de composto ou exaustão de seus gases, é um exemplo de processo acelerado.

Hidrólise: estágio no qual as moléculas orgânicas complexas são quebradas em açúcares, amino-ácidos, e ácidos graxos com a adição de grupos hidroxila.

Acidogênese: continuação de quebra em moléculas menores ocorrendo formação de ácidos graxos voláteis (ex. acético, propiônico, butírico, valérico) e produção de amônia, dióxido de carbono e H2S como subprodutos.

Acetogênese: moléculas simples da acidogênese são digeridas produzindo dióxido de carbono, hidrogênio e ácido acético.

Metanogênese: ocorre formação de metano, dióxido de carbono e água.

que necessita tratamento final, como aterramento, ou incineração, o conceito de reciclagem não deve ser confundido com o de reutilização (JAMES, 1997).

Conforme relata Ferreira (1994), a palavra reciclagem vem do inglês recycle ( $r$ e repetir, e cycle $=$ ciclo) e difundiu-se nos media a partir do final da dé- 
cada de 1980, quando foi constatado que as fontes de petróleo e de outras matérias-primas não renováveis estavam se esgotando rapidamente, e que havia falta de espaço para a disposição de lixo e de outros dejetos na natureza.

Em alguns casos, não é possível reciclar indefinidamente o material, isso acontece, por exemplo, com o papel, que tem algumas de suas propriedades físicas minimizadas a cada processo de reciclagem, devido ao inevitável encurtamento das fibras de celulose. Em outros casos, felizmente, isso não acontece. A reciclagem do alumínio, por exemplo, não acarreta em nenhuma perda de suas propriedades físicas, e esse pode, assim, ser reciclado continuamente (FERREIRA, 1994).

\section{METODOLOGIA}

Ao lidar com a complexidade que envolve as questões ligadas à problemática dos resíduos sólidos urbanos, utilizou-se neste trabalho um exaustivo levantamento bibliográfico cujas fontes de dados secundários encontram-se ancoradas em literatura especializadas sobre o tema, como: livros, artigos, documentos, teses, dissertações, além de banco de dados disponíveis, que retratam o panorama dos resíduos sólidos urbanos. Segundo Marconi e Lakatos (1992), a pesquisa bibliográfica é o levantamento de toda a bibliografia já publicada, tem como finalidade fazer com que o pesquisador entre em contato direto com todo o material escrito sobre um determinado assunto, auxiliando na análise das pesquisas ou na manipulação de suas informações. Para Fonseca,

[...] A pesquisa bibliográfica é feita a partir do levantamento de referências teóricas já analisadas, e publicadas por meios escritos e eletrônicos, como livros, artigos científicos, páginas de web sites. Qualquer trabalho científico inicia-se com uma pesquisa bibliográfica, que permite ao pesquisador conhecer
A partir da análise acerca das formas de tratamento de resíduos sólidos urbanos, observa-se que a Reciclagem é ideal para se lidar com a casca de coco. Segundo Vilhena \& Wells (1998), no Brasil, as empresas já despertam a atençao para o potencial da reciclagem de coco. Além disso, há empresas e pequenos agricultores que queimam as fibras de coco com o objetivo de obter energia para a geraçao de vapor - cada tonelada de biomassa produz em média 1840 kilowatts/hora de energia. As cinzas geradas pela queima sao ricas em óxido de potássio, sendo usadas como adubo para manutençao e plantio dos coqueiros, proporcionando uma reduçao de até $25 \%$ nos gastos com fertilizantes. Esse material também é empregado em fornos de tijolos substituindo a lenha.

o que já se estudou sobre o assunto. Existem, porém, pesquisas científicas que se baseiam unicamente na pesquisa bibliográfica, procurando referências teóricas publicadas com o objetivo de recolher informações ou conhecimentos prévios sobre o problema a respeito do qual se procura a resposta (FONSECA, 2002, p. 32).

Trata-se, portanto, de uma pesquisa de cunho bibliográfico e documental na medida em que se fez uso de diversos tipos de documentos conservados no interior dos órgãos públicos, conforme assinala Fonseca;

[...] A pesquisa documental trilha os mesmos caminhos da pesquisa bibliográfica, não sendo fácil por vezes distingui-las. A pesquisa bibliográfica utiliza fontes constituídas por material já elaborado, constituído basicamente por livros e artigos científicos localizados em bibliotecas. A pesquisa documental recorre a fontes mais diversificadas e dispersas, sem tratamento analítico, tais como: tabelas estatísticas, jornais, revistas, relatórios, documentos oficiais, cartas, filmes, fotografias, pinturas, tapeçarias, relatórios de empresas, vídeos de programas de televisão, etc. (FONSECA, 2002, p. 32). 


\section{CONCLUSÃO}

Desde o seu aparecimento no planeta, o ser humano estabeleceu uma relação bastante complexa com a Natureza. No princípio havia uma unicidade orgânica entre o homem e a natureza, em que o ritmo de trabalho e da vida humana associava-se ao ritmo da natureza. No contexto do modo de produção capitalista, este vínculo é rompido, pois a natureza, antes um meio de subsistência do homem, passa a integrar o conjunto dos meios de produção do qual o capital se beneficia.

No processo de apropriação e de transformação dos recursos pelo homem, através do trabalho, ocorre o processo de socialização da natureza. 0 trabalho torna-se, então, o mediador universal na relação do homem com a natureza, como afirma Marx (2000, p.188): "O trabalho é, num primeiro momento, um processo entre a natureza e o homem, processo em que este realiza, regula e controla por meio da ação, um intercâmbio de materiais com a natureza". Esta forma de se relacionar com o mundo gerou um processo de exploração desenfreada dos recursos naturais do planeta, ao mesmo tempo em que o desenvolvimento tecnológico permitiu melhores condições de vida. Desse modo, o século XXI, que nasce sob a égide da mais nova versão de globalização e das novas tecnologias de informação, assiste à sedimentação uma nova sociedade, sustentada na velocidade e no consumo.

O planeta cada dia mais pede socorro, ao mesmo tempo em que leva a humanidade a buscar alternativas para continuar sobrevivendo. A nova ordem mundial contribui para a geração de miséria, fome da mesma forma que o incentivo ao consumo desenfreado gera cada vez mais lixo, principalmente nas grandes cidades. 0 desafio do homem contemporâneo é buscar formas de viver que permitam o equilíbrio entre o meio ambiente, suas necessidades econômicas e o bem-estar social. Eis o grande desafio de a sociedade utilizar as formas de tratamento acima citadas ou outra que busque a contribuição em diminuir o impacto gerado pelo grande quantidade de resíduos gerada atualmente no nosso planeta.

\section{REFERÊNCIAS}

ASSOCIACAO BRASILEIRA DE NORMAS E TECNICAS. Coletâneas de normas de gestão ambiental: ISSO 14000. Rio de Janeiro: ABNT, 1998.

ASSOCIACAO BRASILEIRA DE NORMAS E TECNICAS. NBR 10004: Resíduos sólidos - classificação. Rio de Janeiro: ABNT, 2004.

ASSOCIACAO BRASILEIRA DE NORMAS E TECNICAS. NBR 10007: Amostragem de resíduos sólidos. Rio de Janeiro: ABNT, 2004d.

BOJADSEN, Minka Ilso. Lixo e reciclagem. São Paulo: Cinco elementos, 1997.

CEMPRE, 1994. 
CONSONI, Ângelo Jose et al. Origem e composição do lixo. In. Lixo municipal: manual de gerenciamento integrado. Brasília: CEMPRE, 2002.

D’ALMEIDA, Maria Luiza Otero (org.) Lixo municipal: manual de gerenciamento integrado. Brasília: CEMPRE, 2002.

FERREIRA, Aurélio Buarque de Holanda. Novo dicionário. Rio de Janeiro: Nova Fronteira, 1999.

FERREIRA, Natalia de M Araujo. A reciclagem do lixo e suas leis. Rio de Janeiro:

FONSECA, J. J. S. Metodologia da pesquisa científica. Fortaleza: UEC, 2002. Apostila.

GONCALVES, P. A reciclagem integradora dos aspectos ambientais, sociais e econômicos. Rio de Janeiro: DP\&A/FASE, 2003.

GUNNERSON, Charles G. Integrated resource recovery anaerobic digestion: principles and practices for biogas systems. Washinton: World Bank, 1986.

IBGE. Banco de dados agregados. Censo agropecuário: 2002. Disponível em www. sidra.ibge.gov.br Acesso em 22 janeiro 2012.

JAMES, Barbara. Lixo e reciclagem. São Paulo: Scipione,1992.

KIEHL, J. E. Fertilizantes orgânicos. Piracicaba: Agronomia Ceres, 1985.

MARCONI, Marina de Andrade; LAKATOS, Eva Maria. Metodologia do trabalho científico. 4. ed. São Paulo: Editora Atlas, 1992.

MEIO AMBIENTE: Conhecer para preservar. Revista Nova Escola, Rio de Janeiro, Edicão168, dez 2003. Edição Especial.

REIS, M. J. L. Gerenciamento ambiental: um novo desafio para a competitividade.

Rio de Janeiro: Quality Marse, 1995.

SILVA, Maria Ester de Castro. Compostagem de lixo em pequenas unidades de tratamento. Viçosa: CPT, 2000. VILHENA, Andre. WELLS, Christopher. Perfil de recicladora de fibras de coco. São Paulo: CEMPRE, 1998. 
1 Doutoranda em Desenvolvimento e Meio Ambiente - Programa de Pós-Graduação em Desenvolvimento e Meio Ambiente (Prodema), da Universidade Federal de Sergipe (UFS), São Cristóvão - SE. Bolsista Fapitec. E-mail: ronisedealmeida@hotmail.com.

2 Prof. Dr. do Dept $^{\circ}$ de Engenharia Agronômica - DEA/Programa de Pós-Graduação em Meio Ambiente e Desenvolvimento e Meio Ambiente (Prodema), da Universidade Federal de Sergipe (UFS), São Cristóvão - SE. E-mail: alceupedrotti@gmail.com.

3 Doutoranda em Desenvolvimento e Meio Ambiente - Programa de Pós-Graduação em Desenvolvimento e Meio Ambiente (Prodema), da Universidade Federal de Sergipe (UFS), São Cristóvão - SE. Bolsista Fapitec. E-mail: daniela.aju@hotmail.com.

4 Doutorando em Desenvolvimento e Meio Ambiente - Programa de Pós-Graduação em Desenvolvimento e Meio Ambiente (Prodema), da Universidade Federal de Sergipe (UFS), São Cristóvão - SE, profo. Do Instituto Federal de Sergipe. E-mail: lcarlosp@oi.com.br. 